\title{
A New Sesquiterpenoid from the Rhizome of Curcuma zedoaria
}

\author{
Sohee Eun, Inho Choi, and Sang Hee Shim* \\ School of Biotechnology, Yeungnam University, Gyeongsan 712-749, Korea. *E-mail: shshim29@ynu.ac.kr \\ Received February 17, 2010, Accepted March 9, 2010
}

Key Words: Curcuma zedoaria, Zingiberaceae, Sesquiterpenoid, Isolation, Structure determination

Curcuma zedoaria Rosc, also known as white turmeric, zedoaria, or gajutsu, is a perennial rhizomatous herb that belongs to the Zingiberaceae family. ${ }^{1}$ The plant is indigenous to Bangladesh, Sri Lanka, and India, and is also cultivated in China, Japan, Brazil, Nepal, and Thailand. ${ }^{1}$ The rhizome of the plant has been used in Japanese and Chinese folk medicine as an aromatic stomachic, emmenagogus, or for the treatment of 'Oketsu' syndrome caused by blood stagnation. ${ }^{2}$ Zedoaria has also been reported to have antimicrobial and antifungal activities, ${ }^{3}$ a larvicidal effect, ${ }^{4}$ and analgesic, ${ }^{5}$ antiallergic, ${ }^{6}$ hepatoprotective, ${ }^{7}$ anti-inflammatory, ${ }^{8}$ antimutagenic, cytotoxic, anticancer, ${ }^{9}$ and antioxidant activities. Previous chemical studies of this plant have revealed the presence of curcuminoids ${ }^{10}$ and different kinds of sesquiterpenoids, ${ }^{1,11-14}$ including furanodiene, furanodienone, zederone, curzerenone, curzeone, germacrone, curcumenol, and zedoaronediol.

The present study describes isolation and structural determination of a new sesquiterpenoid $\mathbf{1}$, named as curcuzederone, along with a known flavonoid, naringenin (2). The chemical structures of these compounds were confirmed, as shown in Fig. 1, by interpretation of measured 1D and 2D NMR spectroscopic data and by comparison of those data with published values. Compound $\mathbf{2}$ was isolated for the first time from this plant.

By analysis of HREIMS, as well as ${ }^{1} \mathrm{H},{ }^{13} \mathrm{C}$, and DEPT NMR data, the molecular formula of compound 1 was determined to be $\mathrm{C}_{15} \mathrm{H}_{20} \mathrm{O}_{5}$ (six unsaturations). Based on DEPT results, eighteen protons were observed attaching to carbons, so that presence of two exchangeable $\mathrm{OH}$ groups was expected. Compound 1 showed ${ }^{1} \mathrm{H}$ and ${ }^{13} \mathrm{C}$-NMR spectra containing signals for two oxymethine groups, three $\mathrm{sp}^{3}$ methylene groups (including one isolated methylene group), two olefine groups, two methyl groups attached to an $\mathrm{sp}^{3}$ quaternary methine, a ketone, and one aromatic methyl group. Accordingly, a tricyclic structure was required for 1 to account for the six unsaturation numbers.

Analysis of ${ }^{13} \mathrm{C}$ NMR $\delta$ values and DEPT data revealed the presence of a methyl-substituted furan ring. An isolated O-CH-

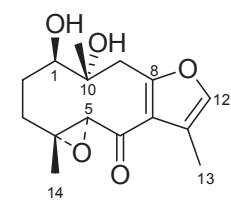

1<smiles>O=C1CC(c2ccc(O)cc2)Oc2cc(O)cc(O)c21</smiles>

2
Figure 1. Chemical structures of compounds 1 and 2.
$\mathrm{CH}_{2}-\mathrm{CH}_{2}$ spin-system corresponding to the $\mathrm{C} 1-\mathrm{C} 2-\mathrm{C} 3$ unit in 1 was assigned on the basis of ${ }^{1} \mathrm{H}-{ }^{1} \mathrm{H}$ COSY data and coupling constants. HMBC correlations of a methyl proton $\left(\delta_{\mathrm{H}} 1.31\right)$ with $C-3$, an oxygenated quaternary carbon $\left(\delta_{\mathrm{C}} 63.7\right)$ and the other oxymethine carbon $\left(\delta_{\mathrm{C}} 63.3\right)$, as well as correlation of oxymethine proton $\left(\delta_{\mathrm{H}} 3.76\right)$ with the carbonyl carbon indicated that a $\mathrm{C} 4$ and $\mathrm{C}-5$ were linked to $\mathrm{C} 1-\mathrm{C} 2-\mathrm{C} 3$ unit and the carbonyl group (C-6). The remainder of the $\mathrm{sp}^{3}$ methylene protons $\left(\delta_{\mathrm{H}} 2.80,3.67\right)$ were correlated with $\mathrm{C}-1$, an oxygenated quaternary carbon $\left(\delta_{\mathrm{C}} 57.9\right)$ and a methyl carbon $\left(\delta_{\mathrm{C}} 16.8\right)$, suggesting that $\mathrm{C} 1$ was linked with that methylene carbon (C-9) through an oxygenated $\mathrm{sp}^{3}$ quaternary carbon $(\mathrm{C}-10)$ bearing a methyl group. In this way, the 10-membered ring system was assigned. In addition, $\mathrm{HMBC}$ correlations of $\mathrm{H}_{2}-9$ with two carbons in the furan ring $\left(\delta_{\mathrm{C}} 122.6\right.$ and 156.1) indicated fusion of the furan ring with the 10 -membered ring at the $\mathrm{C}-7$ and $\mathrm{C}-8$ positions. Finally, the presence of an epoxide ring was presumed to meet the number of unsaturations (tricyclic ring system) and the molecular formula. By comparison of chemical shifts with literature values, the epoxide ring was presumed to be at C-4 and C-5. ${ }^{11-12}$

The relative stereochemistry of $\mathbf{1}$ was established based on the NOESY spectrum. Furthermore, NMR assignments for three geminal methylene groups $\left(\mathrm{H}_{2}-2, \mathrm{H}_{2}-3\right.$, and $\left.\mathrm{H}_{2}-9\right)$ were made by analysis of NOESY data. NOESY correlations between $\mathrm{H}-5$ and $\mathrm{H}_{2}-9$ at $\delta_{\mathrm{H}} 3.67$ indicated that they are placed in the same face of the molecule. As shown in Fig. 2, strong NOESY correlations between $\mathrm{H}-1$ and the other $\mathrm{H}-9$ at $\delta_{\mathrm{H}} 2.80$ indicated that the hydroxyl group at C-1 was in the opposite face to the epoxide group. In addition, strong NOESY correlations between $\mathrm{H}_{3}-14$ and $\mathrm{H}_{3}-15$, as well as absence of NOESY correlations between $\mathrm{H}-1$ and $\mathrm{H}_{3}-15$ suggested that both $\mathrm{H}_{3}-14$ and $\mathrm{H}_{3}-15$ were in the same face as the hydroxyl group at C-1. Thus, the overall chemical structure of $\mathbf{1}$ was determined as shown in Fig. 1. Individual assignments for all methylene proton signals were made on the basis of NOESY correlations. Absolute stereochemistry of 1 was proposed based on CD data, as the Cotton effect associated with the carbonyl and furan groups at $284 \mathrm{~nm}$
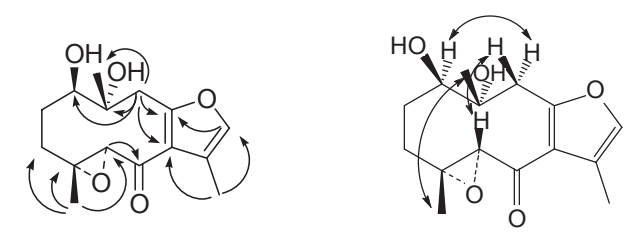

Figure 2. Key HMBC and NOESY correlations observed for curcuzederone (1). 
could be predicted from its chirality on the basis of the helicity rule for skewed dienes. ${ }^{15}$ A strong positive Cotton effect was observed at $284 \mathrm{~nm}$, as shown in zederone, ${ }^{12}$ which suggested the $R$ configuration at both $\mathrm{C}-4$ and $\mathrm{C}-5$, leading to proposal of the overall absolute stereochemistry.

Compound $\mathbf{1}$ is most closely related to zederone, which was isolated from this plant, ${ }^{11-12}$ and differed by replacement of a double bond between $\mathrm{C}-1$ and $\mathrm{C}-10$ with two hydroxyl groups. To the best of our knowledge, compound $\mathbf{1}$ is the only example of a naturally occurring germacrane-type sesquiterpenoid with oxygenations at $\mathrm{C}-1$ and $\mathrm{C}-10$.

On the basis of NMR data, compound $\mathbf{2}$ was identified as naringenin, a flavanone-type flavonoid. ${ }^{16}$ To the best of our knowledge, this is the first report of isolation of a flavonoid from this plant.

In summary, chemical studies of Curcuma zedoaria led to isolation of a new sesquiterpenoid $\mathbf{1}$ and a known flavonoid $\mathbf{2}$. The structures of both compounds were elucidated on the basis of NMR and MS data.

\section{Experimental Section}

General experimental procedures. NMR spectra were recorded using Varian's standard pulse program with a Varian VNS spectrometer at $600 \mathrm{MHz}$. EIMS spectra were recorded with Micromass spectrum (AUTOSPEC, UK). TLC was performed using Kieselgel 60F 254 (Merck) and RP-18 (Whatman). Column chromatography was performed using silica gel (70 230 mesh, Merck). NMR spectra were recorded in $\mathrm{CDCl}_{3}$, and chemical shifts were referenced relative to the corresponding signals $\left(\delta_{\mathrm{H}} 7.24 / \delta_{\mathrm{C}} 77.23\right)$.

Plant material. Dried rhizomes of Curcuma zedoaria were purchased from Daegu Pharmacopoeia Market, South Korea. A voucher specimen was deposited in the Natural product chemistry laboratory of the school of Biotechnology, Yeungnam University.

Isolation. Dried rhizomes of C. zedoaria $(2 \mathrm{~kg})$ were extracted three times with methanol ( $4 \mathrm{~L})$ under reflux for $3 \mathrm{~h}$ to give $\mathrm{MeOH}$ extract (241.2 g). The extract was successively partitioned with $n$-hexane, $\mathrm{CH}_{2} \mathrm{Cl}_{2}$, and EtOAc to yield 50.9, 73.2, and $12.1 \mathrm{~g}$ respectively. The $\mathrm{CH}_{2} \mathrm{Cl}_{2}$-soluble fraction $(73.2 \mathrm{~g})$ was subjected to vacuum liquid chromatography (70 - 230 mesh, Merck) with elution of a gradient of $n$-hexane-ethyl acetate, followed by EtOAc-MeOH gradient, to afford eleven fractions (Fr. $1 \sim$ Fr. 11). Fr. 7 (3.18 g) was further subjected to Sephadex LH-20 column chromatography with successive elution of $n$-hexane- $\mathrm{CH}_{2} \mathrm{Cl}_{2}$ (4:1 $\rightarrow$ 1:4), $\mathrm{CH}_{2} \mathrm{Cl}_{2}$-acetone $(4: 1 \rightarrow 1: 4)$, acetone and $\mathrm{MeOH}$ to give 14 fractions (Fr. 7-1 7-14). Fr. 7-2 was further subjected to silica gel column chromatography with a gradient solvent of $n$-hexane, $\mathrm{CHCl}_{3}$, and EtOAc to give 16 fractions (Fr. 7-2-1 7-2-16). Compound 1 (5 mg) was recrystallized from Fr.7-2-3 under $\mathrm{MeOH}$.
Compound (1): Colorless needles; $[\alpha]_{\mathrm{D}}^{24}+57.78\left(c 0.7 \times 10^{-3}\right.$, $\mathrm{MeOH}$ ); HREIMS (positive ion mode): $m / z 281.1415[\mathrm{M}+\mathrm{H}]^{+}$ (Calcd for $\left.\mathrm{C}_{15} \mathrm{H}_{21} \mathrm{O}_{5}, 281.1389\right)$; UV (MeOH) $\lambda_{\max }(\log \varepsilon) 225$ (3.62), 278 (3.28); $\mathrm{CD}(\mathrm{MeOH}): \Delta \varepsilon 222(-0.09), 281$ (+0.14); ${ }^{1} \mathrm{H}-\mathrm{NMR}\left(\mathrm{CDCl}_{3}, 600 \mathrm{MHz}\right) \delta 7.08(1 \mathrm{H}, \mathrm{s}, \mathrm{H}-13), 3.76(1 \mathrm{H}, \mathrm{s}$, H-5), 3.67 (1H, d, $J=17 \mathrm{~Hz}, \mathrm{H}-9 \beta), 2.91(1 \mathrm{H}$, br d, $J=11 \mathrm{~Hz}$, $\mathrm{H}-1), 2.80(1 \mathrm{H}, \mathrm{d}, J=17 \mathrm{~Hz}, \mathrm{H}-9 \alpha), 2.40(1 \mathrm{H}$, br d, $J=14 \mathrm{~Hz}$, $\mathrm{H}-3 \alpha), 2.22$ (1H, br d, $J=14 \mathrm{~Hz}, \mathrm{H}-2 \alpha), 2.16$ (3H, s, H-13),

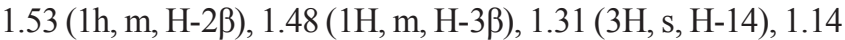
$(3 \mathrm{H}, \mathrm{s}, \mathrm{H}-15) ;{ }^{13} \mathrm{C}-\mathrm{NMR}\left(\mathrm{CDCl}_{3}, 150 \mathrm{MHz}\right) \delta 189.8$ (C-6), 156.1 (C-8), 138.4 (C-12), 123.4 (C-11), 122.6 (C-7), 69.1 (C-1), 63.7 (C-4), 63.3 (C-5), 57.9 (C-10), 39.6 (C-9), 36.1 (C-3), 23.8 (C-2), 16.8 (C-15), 15.3 (C-14), 10.5 (C-13); ${ }^{1} \mathrm{H}-{ }^{1} \mathrm{H}$ COSY correlations $\left(\mathrm{CDCl}_{3}, \mathrm{H}-\# \rightarrow \mathrm{H}-\#\right) \mathrm{H}-1 \leftrightarrow \mathrm{H}-2 \alpha$ and $\mathrm{H}-2 \beta$; H$2 \alpha \leftrightarrow \mathrm{H}-2 \beta, \mathrm{H}-3 \alpha$, and $\mathrm{H}-3 \beta ; \mathrm{H}-2 \beta \leftrightarrow \mathrm{H}-3 \alpha$, and $\mathrm{H}-3 \beta ; \mathrm{H}-3 \alpha \leftrightarrow$ $\mathrm{H}-3 \beta$; H-9 $\alpha \leftrightarrow \mathrm{H}-9 \beta$; HMBC correlations $\left(\mathrm{CDCl}_{3}, \mathrm{H}-\# \rightarrow \mathrm{C}-\#\right)$ : $\mathrm{H}-1 \rightarrow \mathrm{C}-2$; H-5 $\rightarrow$ C-6; H-9 $\beta \rightarrow \mathrm{C}-1,7,8,10 ; \mathrm{H}-9 \alpha \rightarrow \mathrm{C}-1,7$, $8,10,15 ; \mathrm{H}-12 \rightarrow \mathrm{C}-7,8,11 ; \mathrm{H}_{3}-13 \rightarrow \mathrm{C}-7,11,12 ; \mathrm{H}_{3}-14 \rightarrow$ $\mathrm{C}-3,4,5 ; \mathrm{H}_{3}-15 \rightarrow \mathrm{C}-1,9,10$; NOESY correlations $\left(\mathrm{CDCl}_{3}\right.$, $\mathrm{H}-\# \rightarrow \mathrm{H}-\#) \mathrm{H}-1 \leftrightarrow \mathrm{H}-9 \alpha$; $-2 \alpha \leftrightarrow \mathrm{H}-2 \beta, \mathrm{H}-3 \alpha$, and H-3 $\beta$; $\mathrm{H}-3 \alpha \leftrightarrow \mathrm{H}-2 \beta$ and H-3 $\beta$; H-5 ↔ H-9 $\beta$; H-9 $\alpha \leftrightarrow \mathrm{H}-2 \alpha, \mathrm{H}-3 \alpha$, and $\mathrm{H}-9 \beta ; \mathrm{H}_{3}-14 \leftrightarrow \mathrm{H}_{3}-15$.

Acknowledgments. This research was supported by the Yeungnam University research grants in 2008.

\section{References and Notes}

1. Lobo, R.; Prabhu, K. S.; Shirwaikar, A. J. Pharm. Pharmacol. 2009, 61, 13 .

2. Matsuda, H.; Morikawa, T.; Ninomiya, K.; Yoshikawa, M. Bioorg. Med. Chem. 2001, 9, 909.

3. Wilson, B.; Abraham, G.; Manju, V. S.; Mathew, M.; Vimala, B.; Sundaresan, S.; Nambisan, B. J. Ethnopharmacol. 2005, 99, 147.

4. Raghuveer, G.; Ali, M.; Eranna, D.; Ramachandra, S. Indian J. Traditional Knowledge 2004, 2, 375.

5. Navarro, D. F.; Souza, M.; Neto, R. A.; Golin, V.; Niero, R.; Yunes, R. A.; Monache, F. D.; Filho, V. C. Phytomedicine 2002, 9, 427.

6. Matsuda, H.; Tewtrakul, S.; Morikawa, T.; Nakamura, A.; Yoshikawa, M. Bioorg. Med. Chem. 2004, 12, 5891.

7. Matsuda, H.; Ninomiya, K.; Morikawa, T.; Yoshikawa, M. Bioorg. Med. Chem. Lett. 1998, 8, 339.

8. Makabe, H.; Maru, N.; Kuwabara, A.; Kamo, T.; Hirota, M. Nat. Prod. Res. 2006, 20, 680.

9. Seo, W.-G.; Hwang, J.-C.; Kang, S.-K.; Jin, U.-H.; Suh, S.-J.; Moon, S.-K.; Kim, C.-H. J. Ethnopharmacol. 2005, 101, 249.

10. Kuroyanagi, M.; Natori, S. Yakugaku Zasshi 1970, 90, 1467.

11. Hikino, H.; Takahashi, S.; Sakurai, Y.; Takemoto, T. Chem. Pharm. Bull. 1968, 16, 1081.

12. Hikino, H.; Tori, K.; Horibe, I.; Kuriyama, K. J. Chem. Soc. (c) 1971, 4, 688 .

13. Shiobara, Y.; Asakawa, Y.; Kodama, M.; Takemoto, T. Phytochemistry 1986, 25, 1351.

14. Li, M.; Zhou, X.; Zhao, Y.; Wang, D. P.; Hu, X. N. Bull. Korean Chem. Soc. 2009, 30, 2287.

15. Crabbe, P. Chem. Ind. 1969, 917.

16. Albach, R. F.; Redman, G. H. Phytochemistry 1969, 8, 127. 